\title{
CONDIÇÕES ESTRUTURAIS DO NACIONALISMO JAPONÊS RECENTE ${ }^{1}$
}

\author{
Ernani Oda \\ é pesquisador de pós-doutorado no Programa de Ciências Sociais da Universidade Federal de \\ São Paulo (Unifesp). Guarulhos, SP, Brasil. E-mail: <ernanioda@yahoo.com.br>
}

http://dx.doi.org/10.1590/0102-011038/103

Ao mesmo tempo que o leste asiático vem adquirindo nas últimas décadas cada vez mais peso na economia e na política mundial, cresce a preocupação de teóricos e analistas sociais com as tensões recentes que têm marcado as relações entre os países da região, principalmente tendo em vista a proliferação de discursos de cunho nacionalista não só nas classes governantes, mas também nas populações civis (Moore, 2013; Tønesson, 2016). Nesse contexto, o caso específico do nacionalismo japonês tem merecido grande atenção, considerando a intensidade de suas repercussões. Principalmente a partir da década de 1990, ele tem provocado reações inflamadas em países como China e Coreia do Sul, onde fortes protestos têm surgido tanto no nível diplomático quanto em mobilizações populares, gerando dúvidas sobre a estabilidade na região (Glosserman e Snyder, 2015; Reilly, 2012). Meu objetivo neste trabalho é discutir as

\footnotetext{
${ }^{1}$ A pesquisa para a elaboração deste artigo foi realizada com apoio da Coordenação de Aperfeiçoamento de Pessoal de Nível Superior (Capes).
} 
características do nacionalismo japonês atual e as razões que poderiam explicar seu surgimento.

Mas em que consiste esse nacionalismo? Seguindo a interpretação clássica de Gellner (1983, pp. 1-7), o nacionalismo representa uma ideologia ou um movimento preocupado em promover integração política (geralmente através da criação, defesa ou fortalecimento do Estado) a partir de uma suposta base cultural comum. Os discursos associados ao nacionalismo japonês atual também exibem essa lógica, mas o fazem de uma maneira muito particular, que nem sempre é devidamente explicitada, em parte porque as demandas desse nacionalismo tendem a ser bastante diversas. Convém, por isso, mencionar algumas manifestações concretas do discurso nacionalista para daí extrair os termos mais gerais em que ele articula integração política e comunidade cultural.

\section{$12 \quad$ Nacionalismo e revisionismo}

Podemos tomar como primeiro exemplo os discursos recentes de políticos e intelectuais que defendem o aumento da capacidade militar japonesa e uma maior participação do Japão na mediação de conflitos internacionais. Embora a constituição japonesa de 1946 tenha restringido a capacidade militar do país a fins defensivos, fazendo com que o Japão evitasse por muito tempo se envolver diretamente em confrontos fora de seu território, muitos têm argumentado que tais restrições serviram apenas para minar a soberania japonesa e enfraquecer a posição do país no cenário mundial. Isso teria ficado evidente na Guerra do Golfo (19901991), quando o Japão se recusou a enviar tropas para o conflito e foi severamente criticado pelos países ocidentais. Têm surgido, com isso, propostas no próprio governo de rever os princípios da constituição e assumir uma postura militar mais ativa para restaurar o prestígio do Japão na comunidade internacional (Maslow, 2015; Soeya, 2011). 
Outro tipo de discurso de grande impacto diz respeito ao conteúdo da educação escolar no Japão, especialmente com relação ao ensino da história nacional. Segundo essa tese, a história que os japoneses aprendem hoje na escola tende a retratar o passado do país de maneira excessivamente negativa, sobretudo quando trata da violência cometida durante o domínio colonial japonês sobre os demais países da Ásia a partir da segunda metade do século XIX, como o massacre de civis na cidade chinesa de Nanking em 1937, ou a exploração de escravas sexuais de origem coreana durante a Segunda Guerra Mundial. Essa ênfase em questões negativas estaria sabotando o senso de autoestima dos japoneses, e alguns chegam até a negar tais atrocidades. Para eles, seria necessário reformar a educação japonesa a fim de enfatizar aspectos mais positivos da história nacional. Esse tipo de discurso ganhou ímpeto em 1997, quando se formou uma associação para criar livros didáticos de história que refletissem uma visão supostamente mais favorável do passado japonês (Oguma e Ueno, 2003).

Um terceiro exemplo que merece ser mencionado diz respeito à figura mais específica do primeiro-ministro japonês. Trata-se da polêmica em torno de visitas por parte do primeiro-ministro ao santuário xintoísta Yasukuni, um local criado na cidade de Tóquio em 1869 com o propósito de celebrar aqueles que morreram em combate pelo Japão, mas que a partir de 1978 se tornou objeto de polêmica por prestar homenagens também a líderes militares que foram condenados como criminosos de guerra após o fim da Segunda Guerra Mundial. Devido a essa associação do santuário com a memória do militarismo, muitos líderes japoneses passaram a se afastar dele, ou então a apoiá-lo de forma menos ostensiva. Mas em 2001 o então primeiro-ministro Junichiro Koizumi passou a visitar o santuário todos os anos até o fim de seu mandato, em 2006, apesar de receber fortes críticas. Os simpatizantes do santuário aproveitaram a ocasião das 
visitas para difundir o discurso de que o local seria um símbolo da própria integridade e dignidade nacional, e deveria ser honrado pela população e pelos chefes de governo, a exemplo do que fazem as outras nações do mundo com seus heróis de guerra (Breen 2004; Kuroki, 2013, pp. 91-127).

Seria possível mencionar ainda vários outros fenômenos que vêm surgindo desde meados da década de 1990: o surgimento de organizações xenófobas (Higuchi, 2014); o renovado interesse em símbolos nacionais como a bandeira e o hino japoneses (Ukai, 2005); o viés nacionalista de representações em desenhos animados e séries televisivas (Ohsawa 2011); ou então o agravamento de tensões sobre questões territoriais com outros países (Toyoshita, 2012).

Mais do que acumular exemplos, porém, convém retomar aqui a definição de nacionalismo proposta por Gellner e destacar que em todos esses casos há, em primeiro lugar, uma preocupação direta ou indireta com as ações e a imagem do Japão enquanto comunidade política: sua capacidade militar e seu prestígio internacional, a organização do seu sistema educacional, o comportamento de seus chefes de governo. Em segundo lugar, a manutenção dessa unidade política é tida como diretamente relacionada a uma questão cultural que seria, em tese, de interesse de toda a população japonesa: uma reformulação simbólica da imagem pública do Japão através do "revisionismo histórico".

Esse revisionismo defende que, embora a recuperação japonesa após a Segunda Guerra Mundial seja tradicionalmente vista como uma história de sucesso, sobretudo do ponto de vista econômico (e.g. Vogel, 1979), a partir desse período teria havido na realidade uma ênfase exagerada nos erros cometidos pelo Japão até então e, devido a essa imagem distorcida, teriam sido implantados vários mecanismos institucionais e simbólicos destinados a punir injustamente o povo japonês, enfraquecendo assim a influência do país no mundo. As restrições da constituição de 1946, os livros 
didáticos que retratam as atrocidades do colonialismo japonês, e a negligência dos chefes de governo em honrar símbolos nacionais como o santuário Yasukuni ilustrariam essa tendência. Apesar do crescimento econômico e da prosperidade material alcançada desde então, as restrições do pós-guerra teriam imposto aos japoneses uma identidade autodepreciativa, resultando numa postura passiva e submissa no cenário internacional. Para superar essa situação, seria necessário esclarecer primeiro que os erros cometidos pelo Japão até a Segunda Guerra Mundial não teriam sido tão graves como se costuma afirmar. A partir dessa consciência supostamente mais correta da história, seria possível então rever aqueles mecanismos castradores - : a constituição, os livros didáticos, a hesitação dos chefes de governo etc.

Identificando, dessa forma, uma ideologia revisionista como base cultural comum por trás das demandas políticas do nacionalismo japonês atual, podemos não apenas ordenar melhor a diversidade de suas manifestações, mas também começar a entender por que esse nacionalismo tem provocado reações tão fortes nos países vizinhos, especialmente na China e na Coreia do Sul. A maioria das supostas distorções e inverdades históricas que o revisionismo japonês se propõe a retificar está ligada a atrocidades cometidas pelo colonialismo e pelo militarismo japonês justamente nesses países, como o massacre de Nanking ou a exploração de escravas sexuais. Não surpreende, portanto, que o discurso revisionista de negar ou amenizar esses eventos seja recebido com protestos por chineses e coreanos. É certo que, como veremos, há outros fatores em jogo, e as reações nesses países são na realidade mais complexas. Mas a indignação causada pelo revisionismo é um elemento relevante.

Certamente não seria difícil mostrar como a maioria dos "fatos" que esse revisionismo toma por objetivamente válidos encontra na realidade pouco respaldo na historiografia sobre o Japão do pós-guerra (e.g. Dower, 1999; Oguma, 
2002). No entanto, mais do que testar a veracidade do conteúdo desse discurso, o objetivo deste artigo é examinar sua formação e seu desenvolvimento, sem entrar necessariamente no mérito de suas teses. Independentemente dos fundamentos empíricos duvidosos, o impacto desse discurso na sociedade japonesa e no leste asiático como um todo é bastante real, e a dinâmica de sua difusão merece uma análise mais detida.

\section{Explicações para o nacionalismo: "ansiedade" versus "confiança"}

A primeira pergunta a ser feita é: por que esse tipo de nacionalismo surge no Japão a partir dos anos 1990? A causa mencionada com mais frequência é a atmosfera de "ansiedade" que se estabeleceu no país nas últimas décadas, especialmente com o início da crise econômica decorrente do estouro da bolha financeira japonesa no começo da década de 1990 (e.g. Nye, 2012; Takahara, 2010; Yoda, 2006). Segundo esse raciocínio, a estagnação da economia, o aumento no nível de desemprego e a instabilidade política decorrente da crise teriam ajudado a difundir na população uma condição de insegurança, e o discurso inflamado do nacionalismo, ao pregar a retomada de prestígio do Japão, seria um meio de obter certo conforto emocional. O nacionalismo funcionaria no fundo como um mecanismo de compensação diante do relativo declínio da sociedade japonesa.

O apelo dessa interpretação é bastante forte, e podemos encontrar a mesma lógica em estudos mais gerais sobre discursos nacionalistas também fora do Japão (Appadurai, 2006; Beck, 2002). Trata-se de um argumento simples que oferece uma explicação intuitiva sobre as causas do nacionalismo, tanto no nível macro dos processos sociais (a crise econômica), como no nível micro das motivações individuais (ansiedade e desejo de compensação emocional). 
No entanto, há um problema fundamental nessa interpretação que costuma ser negligenciado: durante a década de 1980, muito antes do estouro da bolha financeira, também havia no Japão discursos e práticas revisionistas análogos aos que foram mencionados até aqui. Em 1982 e 1986 foram travados intensos debates sobre os livros didáticos de história usados nas escolas do país, especialmente com relação ao modo como eles tratavam da dominação colonial japonesa na Ásia. Além disso, em 1985 o então primeiro-ministro Yasuhiro Nakasone, considerado de orientação marcadamente nacionalista, também decidiu visitar o santuário Yasukuni, causando grande polêmica. E em 1987 a questão do fortalecimento militar japonês e uma possível afronta à constituição tornaram-se outra fonte de controvérsia, porque o governo de Nakasone decidiu aumentar o orçamento militar japonês numa proporção maior que aquela tida como limítrofe durante todo o período do pós-guerra. Em todos esses casos se manifestou uma lógica claramente revisionista, e é importante lembrar também que nessas ocasiões houve fortes protestos tanto na China como na Coreia do Sul (Nam, 2015, pp. 329-332; Reilly, 2012, pp. 60-75).

Ironicamente, os analistas da época explicavam esse nacionalismo revisionista como consequência da "confiança" dos japoneses na prosperidade de sua economia e na estabilidade de sua estrutura política (Johnson, 1986, p. 563; Muramatsu, 1987, p. 318). Temos, portanto, mais uma explicação simples e intuitiva que articula de maneira aparentemente coerente um conjunto de causas no nível macro (estabilidade econômica) e no nível micro (confiança e necessidade de autoafirmação). Mas o resultado acaba sendo oposto à intepretação anterior, e em vez de um mecanismo de compensação temos nesse caso um mecanismo de autoafirmação. Isso nos deixa num impasse: afinal, a causa do nacionalismo e do revisionismo estaria na confiança ou na ansiedade? Se ambos os fatores levam ao 
mesmo resultado, o mais natural seria concluir que nenhum deles tem na realidade um efeito muito relevante.

Creio ser possível evitar essa confusão se por um momento deixarmos de lado termos como "ansiedade" ou "confiança" e notarmos que, apesar das semelhanças mencionadas acima, o nacionalismo da década de 1980 e o nacionalismo que vem se intensificando desde os anos 1990 são no fundo fenômenos distintos. Embora haja uma demanda revisionista em comum, os sujeitos, os efeitos e principalmente o contexto social desses discursos são bastante diferentes. Nas seções seguintes irei examinar mais detalhadamente os principais pontos de divergência.

Cumpre adiantar aqui, porém, que esta análise irá privilegiar aspectos de caráter macro, relacionados a transformações mais amplas na sociedade japonesa e na política do leste asiático. Não me aprofundarei na questão das motivações individuais que teriam levado as pessoas a aderir ao nacionalismo. Portanto, tomo a presença de indivíduos com essa inclinação nas décadas de 1980 e 1990 como um pressuposto. A ênfase maior será em entender as diferentes condições estruturais que permitiram a essas pessoas expressar suas opiniões publicamente e de maneira organizada.

Não pretendo com isso sugerir que a motivação individual seja menos relevante, nem que os motivos para que certos indivíduos adotem posições revisionistas tenham permanecido inalterados ao longo das últimas décadas. A questão é sem dúvida importante e complexa, mas quando tratada de maneira apressada ou superficial pode acabar gerando apenas mais confusão, a exemplo do que ocorre com as teses que tentam explicar o nacionalismo japonês recente como consequência de "ansiedade" ou de "confiança". Por isso, uma análise de cunho estrutural sobre os diferentes contextos em que surge esse nacionalismo pode servir como ponto de partida para reflexões posteriores mais aprofundadas sobre a motivação concreta dos indivíduos. 


\section{Trajetórias diferentes em períodos diferentes}

Como sugerido acima, o nacionalismo revisionista que ganha força a partir da década de 1990 tem precedentes na década anterior, mas há uma diferença importante no modo como ele se manifesta nesses dois períodos. Tal diferença não está tanto no conteúdo da doutrina revisionista nem mesmo no seu radicalismo, mas no tipo de recepção dessa doutrina na esfera pública. Farei uma descrição mais detalhada nas seções seguintes, mas em linhas gerais é possível dizer que na década de 1980, embora as polêmicas em torno dos discursos nacionalistas estourassem em diversas ocasiões e tivessem um impacto profundo, elas costumavam ser contidas logo em seguida. Havia, portanto, certa intermitência nas controvérsias. A partir dos anos 1990, ao contrário, a tendência passou a ser não apenas de tensão contínua, mas também de escalada dos conflitos.

O que explica a transição de uma atitude contemporizadora para uma postura de confronto? Reforçando o que já foi mencionado na seção anterior, irei analisar a questão a partir de condições estruturais mais amplas que caracterizaram a sociedade japonesa nas décadas de 1980 e 1990. Uma dessas condições se refere obviamente à diferença na situação econômica nas duas épocas: enquanto na década de 1980 a economia japonesa exibia ainda crescimento e estabilidade, a partir da década seguinte ela passou a se enfraquecer. Vimos que muitos analistas dão grande atenção a essa perspectiva, cuja importância de fato não pode ser negada.

Mas há dois fatores igualmente cruciais, muitas vezes esquecidos, que, sem diminuir a relevância dos fatores econômicos, podem ajudar a esclarecer como estes últimos influenciam na difusão do nacionalismo. Trata-se, em primeiro lugar, da estrutura político-partidária japonesa, e em segundo, das relações do Japão com outros países do leste asiático. Justamente por serem negligenciados com frequência, concentrarei minha análise nesses dois fatores, sem esquecer, porém, o modo como eles interagem com as mudanças na esfera econômica. 


\section{Mudanças no cenário político-partidário na década de $\mathbf{1 9 8 0}$}

Uma das características da política japonesa tem sido o longo período de predomínio de um único partido, o Partido Liberal Democrático (PLD). De 1955 a 1993, o partido manteve sozinho o controle do parlamento, e apesar de duas breves interrupções (de 1993 a 1994 e de 2009 a 2012), em ambos os casos o PLD logo voltou ao poder, ainda que através de coalisões. Atualmente, continua a deter uma maioria confortável nas duas casas do parlamento.

Por trás dessa continuidade, porém, há várias e profundas transformações pelas quais passou o PLD e a estrutura político-partidária do Japão em geral. Como veremos, essas transformações tiveram grande impacto na difusão de discursos nacionalistas e demandas revisionistas, especialmente a partir da década de 1980 .

Até os anos 1980 o PLD tinha a maioria no parlamento, mas sua estrutura interna era causa de grandes preocu20 pações para seus líderes. Desde sua origem, o partido era bastante divido, organizando-se em diversas facções que se engajavam em intensas disputas internas (Kitaoka, 2008; Park, 2001). Ao mesmo tempo, as várias facções sentiam necessidade de centralizar o partido em torno de uma liderança única, embora não houvesse acordo sobre qual das facções deveria assumir esse papel; cada uma tentava assim conquistar para si o controle do PLD.

Essa necessidade de centralização se fazia mais premente tendo em vista o receio que os políticos do PLD tinham em relação ao Partido Socialista Japonês (PSJ), principal oposição até a década de 1980. Embora o PSJ nunca tenha de fato ameaçado a domínio do PLD, havia o receio de que a base de apoio do PSJ pudesse eventualmente crescer e mudar a configuração de poder partidário. A base de apoio tradicional do PLD sempre esteve nos eleitores rurais, que até a década de 1950 ainda eram parcela dominante da população japonesa. Com a industrialização e a urbanização do 
Japão a partir desse período, entretanto, havia a perspectiva concreta de aumento das classes industriais operárias, em princípio mais favoráveis a uma agenda socialista (Nakakita, 2014, pp. 56-57).

Os anos seguintes, porém, não confirmaram essas expectativas. Apesar da consolidação de uma sociedade urbana e industrial, o PSJ não obteve mais apoio da população. Pelo contrário, a afluência material e a diversificação dos valores e das práticas culturais iniciada nos anos 1960 atuaram para enfraquecer o apelo das antigas ideologias socialistas (Nakakita, 2014, p. 86; Kitada, 2005). Isso beneficiou o PLD, que podia ainda contar com uma base rural fiel, mas seus membros perceberam que tinham a mesma dificuldade do PSJ em alcançar os novos eleitores urbanos.

Em princípio, o PLD tentou lidar com essa deficiência através de políticas pontuais voltadas a atrair os grupos urbanos, principalmente no campo dos benefícios sociais (Ide, 2013, p. 40). Mas outra iniciativa importante foi o trabalho de lideranças dentro do partido para reformular a própria identidade do PLD. Se antes as disputas entre as diversas facções eram tidas como um mal a ser eliminado, os novos ideólogos passaram a defender que a força do partido estaria justamente nessas divisões. Isso porque uma estrutura centralizada seria rígida demais para dar conta de uma sociedade urbana e industrial diversificada. As facções seriam mais eficientes nesse sentido, podendo atender a uma variedade muito maior de demandas e grupos de interesse, em troca, evidentemente, de recursos para eleger seus respectivos membros e manter sua influência no parlamento. É certo que os conflitos entre as facções continuaram a ser vistos como um problema a ser resolvido, mas a solução não estaria numa estrutura centralizada ou no domínio de uma única facção, e sim num novo estilo de barganha e concessões mútuas entre as diversas facções. Foi essa visão que acabou predominando no PLD a partir da década de 1980 (Nakakita, 2014, pp. 85-88 e 120-128). 
Podemos aqui retomar a questão do nacionalismo. Entre as várias facções do PLD, sempre houve aquelas que reuniam políticos de orientação nacionalista e revisionista, defendendo a necessidade de reverter muitas das políticas adotadas após a Segunda Guerra Mundial, especialmente com relação às restrições militares. No entanto, entre as décadas de 1960 e 1980 o partido esteve sob o controle das facções mais pragmáticas e interessadas em promover o crescimento econômico, o que deixava o revisionismo em segundo plano (Kitaoka, 2008, pp. 115-116).

Porém, uma das consequências daquela nova lógica de barganha entre as facções, consolidada a partir da década de 1980, consistiu justamente em dar mais espaço para as facções nacionalistas que haviam perdido influência nos anos anteriores. Foi o que aconteceu com a facção de Yasuhiro Nakasone, que não por acaso se tornou o principal defensor da nova ideologia. Como já mencionado, Nakasone sempre 22 foi uma figura associada a ideias nacionalistas, mas liderava uma facção menor dentro do PLD. Ele conseguiu chegar ao poder e se tornar primeiro-ministro em 1982 graças a uma aliança com a facção majoritária da época, liderada por Kakuei Tanaka, muito embora essa facção não adotasse o mesmo perfil nacionalista (Nakakita, 2015, pp. 117-128; Wan, 2006, pp. 101-102).

Esse contexto ajuda, por um lado, a explicar por que na década de 1980 havia mais espaço para a manifestação de discursos revisionistas. Para além de um estado psicológico de "confiança" na sociedade japonesa, parece mais relevante enfatizar que a nova estrutura do PLD permitiu que figuras nacionalistas negociassem um espaço maior na esfera política para expressar suas visões. Isso não significa, é claro, que o contexto de estabilidade econômica fosse irrelevante. Para que os diversos grupos de interesse na sociedade pudessem garantir os favores das várias facções, era necessário que eles tivessem uma fonte confiável de recursos, e a afluência da economia japonesa contribuiu para 
isso. Mas não se trata de motivação psicológica ou de "confiança", e sim das condições da cena política da época.

É importante ressaltar, no entanto, que a mesma barganha que beneficiava as facções nacionalistas impunha também limites a elas. Como já mencionei, uma marca dos discursos nacionalistas da década de 1980 é a rapidez com que eram contidos. Agora é possível especificar que um desses mecanismos de controle era exatamente a pressão das facções mais moderadas do PLD.

No caso da visita de Nakasone ao santuário Yasukuni, por exemplo, a pressão da facção majoritária de Tanaka foi decisiva. Além de não exibir a mesma atitude nacionalista de Nakasone, a facção Tanaka era tradicionalmente mais próxima da China, sendo que muitos de seus membros mantinham vínculos fortes com líderes chineses. Por isso mesmo, alguns deles ajudaram na mediação entre Nakasone e o governo chinês. Este exigia que a visita não voltasse a ocorrer, o que de fato se confirmou (Hattori, 2012, pp. 180-183).

Em outros casos, como o dos livros didáticos, Nakasone e seus ministros chegaram mesmo a tomar a iniciativa para conter os nacionalistas. Em 1982 o governo criou uma regra segundo a qual os livros didáticos aprovados pelo poder público deveriam ser mais moderados e levar em consideração possíveis repercussões negativas em países vizinhos. Em 1986, ele praticamente vetou a publicação de conteúdos revisionistas em um livro elaborado por grupos nacionalistas (Kimura, 2014, pp. 126-128). Embora simpatizassem com os nacionalistas, Nakasone e seus aliados precisavam contê-los, visto que o apoio das outras facções poderia se enfraquecer.

É verdade que o papel de contenção das facções mais moderadas não impediu Nakasone de aumentar o orçamento militar japonês em 1987. Por outro lado, isso não resultou numa atuação mais ativa das forças japonesas, o que ficou claro na recusa do Japão em enviar tropas para a Guerra do Golfo em 1990-1991. 


\section{Mudanças no cenário político-partidário a partir da década de 1990}

Uma nova mudança importante na estrutura político-partidária se deu a partir da década de 1990, em grande parte porque a barganha entre as facções acabou gerando problemas sérios para o PLD. Em primeiro lugar, a descentralização do partido, com as diversas facções mantendo relações cada vez mais próximas com diferentes grupos de interesse, acabava favorecendo a corrupção. Foram revelados nessa época vários escândalos que consolidaram uma imagem extremamente negativa das facções (Nakakita, 2014, p. 139). Em segundo lugar, embora a apologia das facções fosse originalmente pensada como estratégia de diversificação para conquistar eleitores heterogêneos das áreas urbanas, o PLD nunca conseguiu fazê-lo, e com os escândalos esse apoio se enfraqueceu ainda mais (Nakano, 2015, p. 77).

Nessa época começaram a se destacar no PLD figuras 24 que defendiam novamente o fim das facções e a formação de uma estrutura centralizada, capaz de vigiar os canais de corrupção, conquistar o eleitorado urbano e estabelecer prioridades para a captação e distribuição dos recursos. Porém, antes que tais figuras pudessem efetuar reformas efetivas, a insatisfação popular levou à saída do PLD do poder em 1993.

O novo governo tinha um discurso bastante crítico ao regime anterior, mas muitos de seus líderes eram na realidade políticos que haviam acabado de deixar o PLD. Os mais influentes compartilhavam até mesmo a crença de que somente uma estrutura política centralizada poderia gerar um regime governável, e com base nisso realizaram uma profunda reforma no sistema eleitoral da câmara baixa do parlamento em 1994. Embora promovida na época em que o PLD estava fora do governo, essa reforma contribuiu para o processo de centralização que muitos membros do próprio PLD vinham propondo. 
Qual o teor da reforma? Até então os representantes eram escolhidos por voto distrital, e cada distrito geralmente elegia de três a cinco representantes. Por isso, o mesmo partido podia indicar vários candidatos para cada distrito, o que o PLD fazia com frequência. Mas isso favorecia a formação de facções, cada uma selecionando, financiando e controlando o próprio candidato. Com a reforma de 1994, cada distrito passou a eleger apenas um representante, o que enfraqueceu muito a influência das facções, pois o partido poderia indicar apenas um candidato por distrito, e essa decisão precisaria agora ser tomada de maneira integrada, dando assim mais controle para a direção geral do partido (Curtis, 1999, pp. 137-170).

Depois que o PLD voltou ao governo em 1994, esse processo de centralização continuou, agora através de uma série de reformas administrativas voltadas a aumentar os poderes do primeiro-ministro, que, como líder do PLD, passaria também a ter mais autonomia para unificar o partido. A criação do Conselho de Política Econômica e Fiscal (Keizai Zaisei Shimon Kaigi), órgão ligado ao primeiro-ministro e relativamente imune à influência das facções, tornou-se um dos símbolos da nova direção adotada (Takenaka, 2006).

Qual a influência da centralização do PLD no nacionalismo? O principal efeito nesse sentido foi que, ao diminuir o poder das facções, a nova estrutura acabou enfraquecendo justamente o principal mecanismo de contenção dos discursos nacionalistas. Nos anos 1980, como vimos, as facções majoritárias tinham um perfil relativamente moderado e procuravam conter os excessos dos nacionalistas. Porém, foram essas mesmas facções que mais perderam com a centralização do partido. Além disso, políticos com a ambição de consolidar a centralização do PLD passaram a ver aqueles grupos nacionalistas minoritários como potenciais aliados contra as facções majoritárias. Apoiar e incentivar discursos nacionalistas se tornava assim um instrumento conveniente de projeção política. 
O caso do primeiro-ministro Junichiro Koizumi a partir dos anos 2000 é o exemplo mais sintomático dessa lógica. Koizumi se tornou a maior imagem da nova estrutura centralizada do PLD, impondo sua agenda contra os setores mais tradicionais do partido e conseguindo realizar a antiga aspiração de conquistar o eleitorado urbano. Uma das estratégias adotadas por ele para chegar à liderança do partido foi justamente atrair o apoio dos grupos nacionalistas dentro do PLD, sobretudo através das já mencionadas visitas que passou a fazer ao santuário Yasukuni (Nakakita, 2014, p. 213).

É interessante notar que muito se discute sobre a posição pessoal de Koizumi com relação ao Yasukuni. Alguns acreditam que ele fazia suas visitas por convicção (Wan, 2006, p. 241), enquanto outros argumentam que o motivo era basicamente instrumental (Nakano, 2015, p. 126). No entanto, mais do que indagar sobre a motivação pessoal de Koizumi, creio ser relevante atentar para o modo como o processo mais amplo de centralização do PLD criou condições para que Koizumi fosse incentivado a se cercar de figuras nacionalistas e revisionistas.

Uma vez no poder e sem a pressão de facções mais moderadas, essas lideranças passaram a contribuir para a escalada do discurso revisionista, seja com relação ao santuário Yasukuni, ao fortalecimento militar do Japão, ou à reforma dos livros didáticos, a fim de difundir uma imagem supostamente mais positiva do passado japonês. A demanda por material revisionista nas escolas não só passou a contar com um movimento organizado a partir de 1997, como teve um livro aprovado pelo governo em 2001; as visitas do primeiro-ministro Koizumi ao santuário Yasukuni continuaram durante todo o seu mandato; e, como vimos, a questão do fortalecimento militar tem avançado cada vez mais, com propostas no próprio governo de reinterpretar ou mesmo alterar a constituição. 


\section{Mudanças no contexto do leste asiático na década de 1980}

Ao analisar as mudanças na estrutura político-partidária japonesa, restringi meu foco à esfera doméstica da questão. É preciso, porém, atentar também para os efeitos do nacionalismo japonês em suas relações internacionais. Tendo em vista que uma das consequências mais sérias do nacionalismo japonês recente são os fortes protestos que ele provoca em países vizinhos, especialmente na China e na Coreia do Sul, é relevante examinar também o efeito que a relação do Japão com esses dois países vem tendo sobre o discurso nacionalista. Como se sabe, com o fim da Segunda Guerra Mundial e do domínio japonês na Ásia, seguiu-se um longo período de interrupção nas relações diplomáticas do Japão com a China e com a Coreia do Sul. No entanto, em 1965 o Japão retomou relações com a Coreia do Sul e em 1972 começou negociações com a China. As diferentes fases desse processo de reaproximação acabaram influenciando o nacionalismo que passou a se manifestar no Japão nas décadas seguintes.

De modo geral, pode-se dizer que, embora no nível individual sempre houvesse pessoas preocupadas em lembrar e discutir o histórico da ação japonesa na Ásia, até a década de 1980 havia condições estruturais que incentivavam os três países a evitar polêmicas sobre os conflitos passados, o que ajudava a conter discursos nacionalistas e revisionistas. $\mathrm{Na}$ década de 1980 alguns desses fatores de contenção perderam sua influência, o que ajuda a explicar por que nessa época o revisionismo ganhou certa projeção. No entanto, outros fatores de contenção continuavam atuantes e acabavam restringindo o ímpeto nacionalista quando este chegava a se manifestar.

O primeiro fator que contribuiu para conter polêmicas nacionalistas até a década de 1980 foi obviamente o contexto da Guerra Fria. No caso da relação entre Coreia do Sul e Japão, que integravam o mesmo bloco liderado pelos 
Estados Unidos, havia a preocupação em consolidar uma parceria militar e econômica que permitisse aos dois países resistir à influência da União Soviética, o que servia para deixar em segundo plano o debate sobre pendências históricas (Glosserman e Snyder, 2015, p. 7). Algo semelhante se deu também na relação entre China e Japão. Embora a China se definisse como comunista, sua crescente resistência à interferência da União Soviética sinalizava para os EUA e seus aliados uma possível reaproximação com o lado chinês. O Japão seguiu essa tendência nas negociações com a China, de modo que a ênfase na ameaça comum soviética ajudou também a diminuir o peso das disputas históricas entre os dois países (Wan, 2006, pp. 86-88).

O outro fator de contenção das tensões nacionalistas era a convergência dos interesses econômicos dos três países. A intensificação do comércio japonês com a China e com a Coreia do Sul contribuiu para expandir as três economias (Lee, 2015; Osawa, 2012). Além disso, o Japão fornecia ajuda financeira para China e Coreia do Sul, o que beneficiava os programas de desenvolvimento e infraestrutura nessas regiões, ao mesmo tempo que favorecia as empresas japonesas, via de regra contratadas para a execução desses projetos (Kimura, 2014, p.73; Wan, 2006, pp. 263-272). As vantagens da cooperação econômica suplantavam assim o apelo de debates morais sobre as atrocidades do domínio colonial japonês.

Finalmente, um terceiro fator de contenção era a relativa cumplicidade das elites políticas nos três países. No caso da relação entre Coreia do Sul e Japão, essa cumplicidade se dava principalmente no nível simbólico, através da figura do ditador Park Chung-hee (1961-1979), que controlava na época o governo sul-coreano. A imagem de Park era a de um militar que, até o fim da Segunda Guerra Mundial, havia colaborado com a dominação japonesa na Coreia, de modo que insistir nas atrocidades das forças japonesas era algo que em princípio minaria a autoridade não só de Park, mas do próprio regime. 
Havia, portanto, um contexto geral que favorecia a supressão desse tipo de questionamento (Kimura, 2014, p. 50).

Quanto ao vínculo entre China e Japão, a proximidade das classes dirigentes era ainda mais concreta. Havia uma rede de contato e influência, muitas vezes sustentada por relações pessoais entre a cúpula do Partido Comunista da China e a do PLD. Estabelecia-se assim um elo entre figuras proeminentes, como Deng Xiaoping e Zhou Enlai do lado chinês, e a já mencionada facção Tanaka no lado japonês. Esses políticos e burocratas do alto escalão atuavam para melhorar a relação entre os dois países em grande parte porque muitos deles tinham sua base de apoio nas elites econômicas que se beneficiavam da parceria econômica entre China e Japão (Wan, 2006, pp. 99-105). Não era de interesse desses líderes, portanto, que atritos a respeito de demandas nacionalistas comprometessem tal cooperação.

No entanto, a partir da década de 1980 o cenário no leste asiático começa a se alterar, o que traz implicações importantes para a interação do Japão com seus vizinhos chineses e sul-coreanos. Do ponto de vista da relação com a Coreia do Sul, é importante ressaltar o fim do regime de Park Chung-hee e o novo governo de Chun Doo-hwan (1979-1988). O país continuou sob um regime autoritário, mas Chun, ao menos formalmente, procurou se distanciar do legado de Park e de outras figuras associadas ao Japão, o que em princípio lhe permitia assumir uma atitude mais crítica perante questões históricas envolvendo a memória das atrocidades japonesas (Kimura, 2014, p. 108). Já no caso da China, uma mudança importante a partir dos anos 1980 foi a relativa redução na tensão entre esse país e a União Soviética. Com isso diminuía a dependência chinesa de uma aliança com o Japão e com o bloco capitalista de modo geral, o que acabava também abrindo maior espaço para que a China adotasse posturas mais severas diante do Japão (Wan, 2006, p. 89). 
Essa posição mais assertiva na China e na Coreia do Sul se tornou visível quando passaram a surgir manifestações cada vez mais explícitas do discurso nacionalista japonês, como na polêmica sobre os livros didáticos de história, a visita do primeiro-ministro Nakasone ao santuário Yasukuni e o aumento do orçamento militar. A Coreia do Sul foi particularmente ativa no caso dos livros didáticos, exigindo explicações do embaixador japonês e formando um grupo de pesquisa para investigar melhor o conteúdo dos materiais didáticos no Japão (Kimura, 2014, p. 86). A China, por sua vez, teve um papel marcante na controvérsia sobre a visita de Nakasone ao Yasukuni, criticando duramente o primeiro-ministro (Wan, 2006, p. 96).

Porém, como sugeri, muitos dos fatores que até então haviam contido as tensões entre os três países ainda permaneciam de pé. Acima de tudo, os interesses econômicos em manter a parceria comercial e os programas de ajuda oficial continuavam sendo preocupações centrais. Além disso, as elites políticas ainda mantinham uma relação de relativa cooperação. No caso da Coreia do Sul, por exemplo, embora o regime de Chun procurasse se distanciar da figura de Park e de vínculos com o Japão, havia ainda entre os aliados de Chun líderes influentes, como Kim Jong-pil, que tinham um histórico de colaboração com as lideranças japonesas, de modo que um discurso de confronto aberto ao Japão não era totalmente factível (Kimura, 2014, p. 173). Já no caso da China, as redes de contato entre o Partido Comunista e o PLD permaneciam ativas. Como já mencionado, uma das condições que permitiram conter a crise iniciada pela visita de Naksone ao Yasukuni foram justamente essas redes, que após intensas negociações informais conseguiram convencer o primeiro-ministro a desistir de continuar suas visitas (Hattori, 2012, pp. 180-183).

A década de 1980 assistiu, assim, à formação de condições que, se por um lado permitiam que o passado de 
dominação colonial do Japão passasse a ser mais discutido e questionado do que havia sido até então, por outro, preservavam ainda fatores de contenção que contribuíam para evitar uma escalada nos níveis de tensão.

\section{Mudanças no contexto do leste asiático a partir da década de 1990}

Uma das características mais marcantes nas relações do Japão com a China e com a Coreia do Sul a partir de 1990 foi uma progressiva erosão dos antigos fatores de contenção que permitiam controlar o impacto negativo do nacionalismo japonês na região.

Primeiramente, o fim da Guerra Fria eliminou o papel estabilizador que a ameaça comum da União Soviética desempenhava nas relações entre os três países. Sem essa ameaça, tornava-se mais difícil colocar os conflitos desencadeados pelos discursos nacionalistas no Japão em segundo plano (Glosserman e Snyder, 2015; Yahuda, 2014).

A segunda mudança foi uma reconfiguração dos interesses econômicos nos três países. Embora se mostrassem ainda dispostos a manter uma relação de cooperação, a posição de cada um deles nessa parceria começou a se alterar com o notável crescimento da Coreia do Sul e da China de um lado, e o relativo declínio do Japão, de outro. Nesse processo, embora a participação japonesa no comércio exterior chinês e sul-coreano permanecesse importante em termos absolutos, seu peso relativo diminuiu sensivelmente devido à grande diversificação desses dois mercados, que passaram a expandir suas parcerias. Ao mesmo tempo, a crise econômica japonesa levou à redução e, por fim, à eliminação dos programas de ajuda oficial para a Coreia do Sul nos anos 1990, e para a China em meados dos anos 2000. Isso serviu para relativizar a interdependência econômica dos três países, que passaram a se ver cada vez mais como concorrentes e rivais (Kimura, 2014, pp. 69-71; Wan, 2006, p. 79). 
Por último, é preciso destacar o enfraquecimento dos antigos vínculos entre as lideranças políticas. $\mathrm{O}$ caso da relação entre China e Japão é representativo dessa tendência. Na época, muitos dos políticos e burocratas do alto escalão que intermediavam o diálogo entre o Partido Comunista da China e o PLD começaram a se retirar de cena (Wan, 2006, p. 279). E como foi exposto, a própria estrutura do PLD sofreu uma profunda transformação, diminuindo radicalmente a influência das antigas facções próximas ao governo chinês.

As relações entre Coreia do Sul e Japão também passaram a sinalizar um atrito maior entre suas elites políticas. O processo sul-coreano de democratização, a partir do final da década de 1980 e começo de 1990, foi o catalisador das mudanças. Enquanto os regimes autoritários de Park e Chun permaneciam reticentes em adotar uma postura mais crítica diante do nacionalismo japonês, visto que seus líderes tinham vínculos históricos com o Japão, os governos democráticos que se seguiram foram se tornando cada vez mais independentes da influência japonesa. Isso se fez especialmente visível a partir de 1993, com o governo de Kim Young-sam, que procurou se afastar do legado dos regimes autoritários anteriores, assumindo, ainda que muito gradualmente, uma atitude mais crítica com relação ao Japão (Kimura, 2014, p. 188-207).

Dessa forma, aqueles fatores de contenção que até os anos 1980 ainda contribuíam para que os debates sobre o passado de dominação japonesa na Ásia permanecessem em níveis administráveis foram em grande parte eliminados. $\mathrm{O}$ resultado disso foi a escalada dos conflitos a partir da década de 1990, com discursos nacionalistas cada vez mais agressivos no Japão e protestos cada vez mais indignados na China e na Coreia do Sul.

As visitas do primeiro-ministro Koizumi ao santuário Yasukuni foram um exemplo claro da ausência dos antigos 
fatores de contenção. Diferentemente do que havia corrido com Nakasone em 1985, quando líderes chineses e japoneses conseguiram controlar a crise, no caso de Koizumi esses canais já não tinham a mesma relevância. Membros da antiga facção Tanaka ainda tentaram convencer Koizumi a desistir de continuar suas visitas. Mas no novo contexto, a facção já não tinha capacidade para intervir. E num mundo em que Japão e China surgiam mais como rivais do que colaboradores econômicos, havia menos incentivos para que o lado chinês contivesse suas críticas. As visitas de Koizumi não cessaram, e a tensão continuou a se acentuar, a ponto de que reuniões entre líderes do governo chinês e japonês fossem canceladas (Wan, 2006, pp. 239-242; cf. Kamo, 2012).

As relações com a Coreia do Sul exibiram uma tendência semelhante, o que pôde ser visto com nitidez nos debates sobre a questão das escravas sexuais de origem coreana recrutadas com a participação do exército japonês até a Segunda Guerra Mundial. O tema veio a se tornar um dos pontos mais controversos dos novos livros didáticos de história elaborados por organizações nacionalistas japonesas na década de 1990, quando os revisionistas passaram a negar ou então minimizar os depoimentos dessas mulheres. Vale notar que, quando a discussão começou de fato a ganhar força no começo da década de 1990, o governo sul-coreano ainda mantinha uma postura conciliatória em relação ao Japão, o que muitas vezes frustrava os movimentos feministas e as associações civis na Coreia do Sul. Havia até um projeto para criar um fundo financiado pelo Japão com o objetivo de encerrar os debates. Na Coreia do Sul, os ativistas eram contrários a esse tipo de medida, mas o governo se mostrava receptivo, pois embora o processo sul-coreano de democratização já tivesse se iniciado, foi apenas em 1993 que se deu a ruptura efetiva com os regimes autoritários anteriores. E de fato, a partir dessa época o governo sul-coreano se tornou mais assertivo perante o Japão quanto ao tema das escravas 
sexuais. A própria proposta japonesa para criar um fundo acabou rejeitada pelo novo governo democrático, e os conflitos em torno da questão se agravaram nos anos seguintes, dificultando as relações diplomáticas entre os dois países (Kimura, 2014, p. 208; Park, 2015).

\section{Conclusão}

Argumentei neste trabalho que podemos entender melhor o discurso revisionista do nacionalismo japonês recente se, antes de falarmos em estados psicológicos de "ansiedade" e "confiança", atentarmos primeiro para as condições estruturais que permitiram que esse discurso surgisse de maneira intermitente na década de 1980 e ganhasse força na década de 1990. Dentre tais condições, destaquei duas: a transformação da estrutura político-partidária japonesa e as mudanças nas relações do Japão com a China e a Coreia do Sul.

Nos anos 1980, a estrutura descentralizada do PLD deu mais espaço para que facções nacionalistas dentro do partido expressassem sua visão revisionista. Além disso, os vínculos entre China, Coreia do Sul e Japão, que vinham se fortalecendo desde as décadas anteriores, passaram por um período de revisão, com a troca de regime na Coreia do Sul e mudanças na política de segurança chinesa. Isso abriu mais espaço para que os três países voltassem a discutir a responsabilidade do Japão por atrocidades cometidas contra seus vizinhos asiáticos até a Segunda Guerra Mundial.

Ao mesmo tempo, porém, havia ainda condições que incentivavam os três países a conter os conflitos, como a necessidade de cooperação econômica e a proximidade entre suas elites políticas. Além disso, a mesma descentralização do PLD que beneficiava as facções nacionalistas as submetia à pressão de facções mais moderadas. Com isso, embora houvesse mais manifestações do discurso 
revisionista, existiam também fatores de contenção que ajudavam a impedir a escalada dos conflitos.

A partir da década de 1990, esses fatores de contenção são praticamente eliminados. A centralização do PLD é prejudicial às facções mais moderadas e favorece figuras nacionalistas dentro do partido. No campo externo, a rivalidade entre China, Coreia do Sul e Japão se fortalece, tanto do ponto de vista econômico quanto político. Nesse novo contexto é mais difícil encontrar uma base comum para o diálogo, e as tensões se tornam mais contínuas e intensas.

Como ressaltei anteriormente, a ênfase nessas condições estruturais não significa que as motivações individuais não sejam relevantes na formação do nacionalismo japonês atual. Sem dúvida, é importante indagar por que certos indivíduos ou certas facções no Japão adotam posições nacionalistas, e por que determinadas pessoas e grupos nos países vizinhos protestam contra tais posições. Esse tipo de questionamento está além da perspectiva adotada neste artigo, mas creio que a análise das condições estruturais proposta aqui pode servir de ponto de partida para reflexões mais aprofundadas sobre as motivações individuais dos nacionalistas, sem reduzi-las a impressões do senso comum sobre "ansiedade" ou "confiança".

\section{Ernani Oda}

É pesquisador de pós-doutorado no Programa de Pós-Graduação em Ciências Sociais da Universidade Federal de São Paulo (Unifesp). Guarulhos, SP, Brasil.

\section{Bibliografia}

APPADURAI, Arjun. 2006. Fear of small numbers: an essay on the Geography of Anger. Durham: Duke University Press.

BECK, Ulrich. 2002. The cosmopolitan society and its enemies. Theory,

Culture and Society, v. 19, n. 1-2, pp. 17-44.

BREEN, John. 2004. The dead and the living in the land of peace.

Mortality, v. 9, n. 1, pp. 76-93. 
CURTIS, Gerald L. 1999. The logic of Japanese politics: leaders, institutions, and the limits of chance. New York: Columbia University Press.

DOWER, John W. 1999. Embracing defeat: Japan in the wake of World War II. New York: W. W. Norton.

GELLNER, Ernest. 1983. Nations and nationalism. Oxford: Basil Blackwell. GLOSSERMAN, Brad; SNYDER, Scott A. 2015. The Japan-South Korea identity clash: East Asian security and the United States. New York: Columbia University Press.

HATTORI, Ryuji. 2012. Nakasone-Hu Yaobang kankei to rekishi mondai. In: TAKAHARA, Akio; HATTORI, Ryuji (orgs.). Nitchû kankeishi 19722012: Seiji. Tokyo: Tokyo Daigaku Shuppankai, pp. 167-196.

HIGUCHI, Naoto. 2014. Nihongata haigaishugi: zaitokukai, gaikokujin sanseiken, Higashi Ajia chiseigaku. Nagoya: Nagoya Daigaku Shuppankai.

IDE, Eisaku. 2013. Nihon zaisei: tankan no shishin. Tokyo: Iwanami.

JOHNSON, Chalmers. 1986. Reflections on the dilemma of Japanese defense. Asian Survey, v. 26, n. 5, pp. 557-572.

KAMO, Tomoki. 2012. Koizumi naikaku to nashonarizumu no kôyô. In: TAKAHARA, Akio; HATTORI, Ryuji (orgs.). Nitchû kankeishi 1972-2012: Seiji. Tokyo: Tokyo Daigaku Shuppankai, pp. 371-415.

KIMURA, Kan. 2014. Nikkan rekishi ninshiki mondai to wa nanika. Kyoto: Minerva.

KITADA, Akihiro. 2005. Warau Nihon no "nashonarizumu”. Tokyo: NHK Books.

KITAOKA, Shinichi. 2008. Jimintô: seikentô no 38 nen. Tokyo: Chuokoron Shinsha.

KUROKI, Maiko. 2013. Nationalism in Japan's contemporary foreign policy: a consideration of the cases of China, North Korea, and India. PhD thesis. 345 f. London: London School of Economics and Political Science. Disponível em: <https://goo.gl/fnbm88>. Acesso em: 5 abr. 2018. LEE, Won Deok. 2015. Nikkan kankei 1965 nen taisei no kiseki: kako to genzai no shômei. In: KIMIYA Tadashi; LEE Won Deok (orgs.). Nikkan kankeishi 1965-2015: Seiji. Tokyo: Tokyo Daigaku Shuppankai, pp. 15-38.

MASLOW, Sebastian. 2015. A blueprint for a strong Japan? Abe Shinzo and Japan's evolving security system. Asian Survey, v. 55, n. 4, pp. 739-765.

MOORE, Aaron William. 2013. Nationalism in Northeast Asia since 1945. In: BREULLY, John (org.). The Oxford handbook of the history of nationalism. Oxford: Oxford University Press, pp. 453-471. 
MURAMATSU, Michio. 1987. In search of national identity: the politics and policies of the Nakasone administration. Journal of Japanese Studies, v. 13, n. 2, pp. 307-342.

NAKAKITA, Koji. 2014. Jimintô seiji no henyô. Tokyo: NHK Books.

NAKANO, Koichi. 2015. Ukeika suru Nihon seiji. Tokyo: Iwanami.

NAM, Sang-Gu. 2015. Rekishi mondai to Nikkan kankei. In: KIMIYA Tadashi; LEE Won Deok (orgs.). Nikkan kankeishi 1965-2015: Seiji. Tokyo: Tokyo Daigaku Shuppankai, pp. 323-348.

NYE, Joseph. 2012. Japan's nationalism is a sign of weakness. Financial Times. Disponível em: <https:/ /goo.gl/4CLF1L>. Acesso em: 5 abr. 2018.

OGUMA, Eiji. 2002. Minshu to aikoku: sengo Nihon no nashonarizumu to kôkyôsei. Tokyo: Shin'yosha.

OGUMA, Eiji; UENO, Yoko. 2003. "Iyashi” no nashonarizumu. Tokyo: Keio Gijuku Daikaku Shuppankai.

OHSAWA, Masachi. 2011. Kindai Nihon no nashonarizumu. Tokyo: Kodansha. OSAWA, Takeshi. 2012. Zenshi 1945-51 nen. In: TAKAHARA, Akio;

HATTORI, Ryuji (orgs.). Nitchû kankeishi 1972-2012: Seiji. Tokyo: Tokyo Daigaku Shuppankai, pp. 5-39.

PARK, Cheol Hee. 2001. Factional dynamics in Japan's LDP since political reform: continuity and change. Asian Survey, v. 41, n. 3, pp. 428-461.

2015. Korea-Japan relations under deep stress. In: ROZMAN, Gilbert (org.). Asia's alliance triangle: US-Japan-South Korea relations at a tumultuous time. Basingstoke: Palgrave Macmillan, pp. 87-104.

REILLY, James. 2012. Strong society, smart state: the rise of public opinion in China's Japan policy. New York: Columbia University Press.

SOEYA, Yoshihide. 2011. A "normal” middle power: interpreting changes in Japanese security policy in the 1990s and after. In: SOEYA, Yoshihide et al. (orgs.). Japan as a "normal country"? A nation in search of its place in the world. Toronto: University of Toronto Press, pp. 72-97.

TAKAHARA, Motoaki. 2010. Teema-betsu kenkyû dôkô: nashonarizumu. Shakaigaku Hyôron, v. 61, n. 2, pp. 206-215.

TAKENAKA, Harukata. 2006. Shushô shihai: Nihon seiji no henbô. Tokyo: Chuokoron Shinsha.

TØNNESSON, Stein. 2016. Will nationalism drive conflict in Asia?. Nations and Nationalism, v. 22, n. 2, pp. 232-242.

TOYOSHITA, Narahiko. 2012. Senkaku to wa nanika. Tokyo: Iwanami.

UKAI, Satoshi. 2005. Reflection beyond the flag: why is the hinomaru flag 'auspicious/foolish'? In: CALICHMAN, Richard F. (org.). Contemporary Japanese thought. New York: Columbia University Press, pp. 281-293. 
VOGEL, Ezra F. 1979. Japan as number one: lessons for America. Cambridge, MA: Harvard University Press.

WAN, Ming. 2006. Sino-Japanese relations: interaction, logic, and transformation. Washington : Woodrow Wilson Center Press; Stanford: Stanford University Press.

YAHUDA, Michael. 2014. Sino-Japanese relations after the Cold War. London: Routledge.

YODA, Tomiko. 2006. A roadmap to millennial Japan. In:

HAROOTUNIAN, Harry; YODA, Tomiko (orgs.). Japan after Japan: social and cultural life from the recessionary 1990s to the present. Durham, Duke University Press, pp. 16-53. 


\section{)}

\section{CONDIÇÕES ESTRUTURAIS DO NACIONALISMO JAPONÊS RECENTE}

ERNANI ODA

Resumo: Este artigo analisa o fortalecimento de discursos nacionalistas no Japão a partir da década de 1990, bem como suas repercussões internas e externas. Embora seja comum interpretar esse nacionalismo como um mecanismo psicológico de compensação para lidar com a "ansiedade" deflagrada pela crise econômica que passou a afetar a sociedade japonesa na época, este trabalho argumenta que podemos compreender melhor o fenômeno como o resultado de mudanças recentes nas condições estruturais mais amplas da sociedade japonesa. Serão discutidos dois fatores estruturais em particular: no âmbito interno, o cenário político-partidário japonês, e, no âmbito externo, a posição do Japão no contexto do leste asiático, tendo em vista especialmente sua interação com a China e com a Coreia do Sul.

Palavras-chave: Nacionalismo; Revisionismo; Japão; Ásia; Tensões Regionais.

\section{THE STRUCTURAL CONDITIONS OF CURRENT JAPANESE NATIONALISM: PARTY POLITICS AND THE REGIONAL CONTEXT}

Abstract: This article examines the intensification of nationalist discourses in Japan since the 1990s and their effects at both the domestic and the international level. Although this trend is often interpreted as a psychological mechanism to compensate for the "anxiety" provoked by the economic crisis that started in Japan during this period, it is argued that this process is better understood as the result of recent changes in the more encompassing structural conditions pervading Japanese society. Two of these conditions merit special attention: at the domestic level, Japanese party politics, 
Resumos $\mid$ Abstracts

and at the international level, Japan's position in the East Asian regional context, particularly in regard to China and South Korea. Keywords: Nationalism; Revisionism; Japan; Asia; Regional tensions. Recebido: 23/11/2017 Aprovado: 02/04/2018 